\title{
BMJ Open Patterns of prescription opioid use in Swiss emergency department patients and its association with outcome: a retrospective analysis
}

\author{
Bertram K Woitok (1) , ${ }^{1}$ Petra Büttiker, ${ }^{1}$ Svenja Ravioli, ${ }^{1}$ Georg-Christian Funk, ${ }^{2}$ \\ Aristomenis K Exadaktylos, ${ }^{3}$ Gregor Lindner $^{1}$
}

To cite: Woitok BK, Büttiker P, Ravioli S, et al. Patterns of prescription opioid use in Swiss emergency department patients and its association with outcome: a retrospective analysis. BMJ Open 2020;10:e038079. doi:10.1136/ bmjopen-2020-038079

- Prepublication history for this paper is available online. To view these files, please visit the journal online (http://dx.doi. org/10.1136/bmjopen-2020038079).

Received 27 February 2020 Revised 23 August 2020 Accepted 24 August 2020

A) Check for updates

(C) Author(s) (or their employer(s)) 2020. Re-use permitted under CC BY-NC. No commercial re-use. See rights and permissions. Published by BMJ.

1Department of Internal and Emergency Medicine, Bürgerspital Solothurn,

Solothurn, Switzerland

${ }^{2}$ Karl-Landsteiner-Institute for Lung Research and Pulmonary Oncology, Wilhelminenspital, Vienna, Austria

${ }^{3}$ Department of Emergency

Medicine, Inselspital Bern, Bern, Switzerland

Correspondence to Dr Bertram K Woitok; bertram.woitok@spital.so.ch

\section{ABSTRACT}

Objectives We aimed to clarify the prevalence, indications, analgesic comedications and complications of prescription opioid use in patients presenting to a large emergency department (ED).

Design Retrospective chart review.

Setting Large, interdisciplinary ED of a public hospital. Participants All patients aged $\geq 18$ years presenting between 1 January 2017, and 31 December 2018, with documentation on medication were included.

Interventions None.

Primary and secondary outcome measures Prevalence rates for prescription opioid use and its indication. Prevalence of analgesic comedications in prescription opioid users. Hospitalisation rate, 72 hours ED reconsultation rate, 30-day rehospitalisation rate, inhospital mortality.

Results A total of 26224 consultations were included in the analysis; 1906 (7.3\%) patients had prescriptions for opioids on admission to the ED. The main indications for opioid prescriptions were musculoskeletal disease in $1145(60.1 \%)$ patients, followed by neoplastic disease in $374(19.6 \%)$ patients. One hundred fifty-four (8.2\%) consultations were directly related to opioid intake, and $50.1 \%$ of patients on opioids also used other classes of analgesics. Patients on prescription opioids were older (76 vs 62 years, $p<0.0001$ ) and female individuals were overrepresented (58 vs $48.9 \%, p<0.0001$ ). Hospitalisation rate (78.3 vs $49 \%, p<0.0001$ ), 72 hours ED reconsultation rate ( 0.8 vs $0.3 \%, p=0.004), 30$-day rehospitalisation rate $(6.2$ vs $1.5 \%, p<0.0001)$ and in-hospital mortality ( 6.3 vs $1.6 \%$, $\mathrm{p}<0.0001$ ) were significantly higher in patients with opioid therapy than other patients. In 25 cases (1.3\%), admission to the ED was due to opioid intoxication.

Conclusions Daily prescription opioid use is common in patients presenting to the ED. The use of prescription opioids is associated with adverse outcomes, whereas intoxication is a minor issue in the studied population.

\section{INTRODUCTION}

Opioids are widely used in ambulatory and hospitalised patients, but there is concern regarding their liberal prescription before alternative approaches have proven ineffective. ${ }^{1}$ The three major concerns are: creating
Strengths and limitations of this study

- The large data set provides high power.

- First European data on individual dosages and indications of prescription opioids.

- Potential significant selection bias due to missing medication data.

- Single-centre study; therefore, the results are not necessarily generalisable.

dependency, misuse of dispensed drugs and adverse events. Although short-term use seems to be unlikely to cause dependency, ${ }^{2}$ there is evidence that opioid prescriptions in the emergency department (ED) can lead to dependency in susceptible patients. ${ }^{3-5}$ Considering the recent increased prevalence of prescription opioid analgesics in the USA, opioid misuse is a major concern. ${ }^{6}$ In Europe, prescription opioids are increasingly used, but with 8967 defined daily doses (DDD) per million inhabitants in Europe (11850 for Switzerland) compared with 16491 DDD in the USA in 2016, their prevalence is lower in Europe than the USA. ${ }^{7}$ Data on prescription opioid misuse in Europe are scarce. Kalkman et al studied opioid misuse in the Netherlands and found a prevalence of 5.6 per 100000 inhabitants in $2015,{ }^{8}$ whereas data from the USA showed a prevalence of 22.1 per 100000 inhabitants in $2013 .{ }^{9}$ In Canada, opioid overdosing increased in the past 10 years, reaching 15.6 per 100000 in 20162017. ${ }^{10}$ The differences between Europe and the USA are especially pronounced when comparing opioid-related deaths; although in Europe, deaths were stable at approximately 1.2 per 100000 inhabitants per year in 2007 and 2016, there were 15 deaths per 100000 inhabitants from opioid overdose in the USA in $2017 .^{8}$ 
Physicians are also confronted with other downsides of opioid use. Adverse events such as nausea, vertigo and constipation have been widely reported. Moreover, it has been shown that patients undergoing opioid therapy have significantly decreased cognitive function as measured by the Mini-Mental State Examination and Montreal Cognitive Assessment. ${ }^{11}$ In addition, it has been found that patients presenting with vertigo, who were also prescribed opioids, were at significantly higher risk of fractures than patients who were not prescribed opioids. ${ }^{12}$ The incidence of adverse events from opioids prescribed in the ED is generally low and associated with age, sex and route of administration. ${ }^{13}$ Another point to consider is the accumulation of opioid-metabolites in patients with impaired renal function. Hydromorphone is considered a safer treatment than morphine and oxycodone. ${ }^{14}$

Most available data on prescription opioid use are from the USA, where the lay press, experts and even government officials are talking about a national crisis due to opioid overuse. Although little data are available from central Europe, it is likely that there are considerable national discrepancies in the patterns of opioid use. To the best of our knowledge, no single study on the prevalence of prescription opioid use and its indications and association with the outcome from a large heterogenic patient collective with data from central Europe exists.

Therefore, we aimed to evaluate: (1) the prevalence of outpatient prescription opioid use and analgesic comedication in opioid users. Furthermore, we investigated (2) the indications and (3) the association with adverse outcomes of prescription opioid use in a large, heterogenic collective of patients presenting to the ED of a large public hospital.

\section{METHODS}

\section{Study design and setting}

The Department of Emergency Medicine of the Bürgerspital Solothurn is an interdisciplinary ED, treating approximately 35000 patients per year. We performed a retrospective chart review of all admissions to our ED between 1 January 2017 and 31 December 2018. The study protocol is available in the appendix (online supplemental file 1).

\section{Selection of participants}

All patients admitted to our ED with documentation of home medication in their electronic patient records were included in the analysis. Chart reviews were performed on all included patients, and the data extraction form can be found in the appendix (online supplemental file 2). The following substances were labelled as opioid therapy and the dose per 24 hours was extracted: morphine, hydromorphone, fentanyl, buprenorphine, tramadol, dihydrocodeine, levomethadone, methadone, tapentadol, tilidin, oxycodone and oxycodone/naloxone.

Patients younger than 18 years of age and patients who generally withdrew the approval to use their data for any scientific purposes written or verbally were excluded from the analysis.

\section{Measurements}

Demographic data were gathered from all included patients on comorbidities, current medication, indications for opioid prescriptions, reason for current ED consultation and relation to opioid intake, need to administer naloxone, need for hospitalisation, 72-hour ED reconsultation, hospital length of stay, mortality, presence of alcohol and/or benzodiazepine cointoxication in patients taking opioid analgesics presenting with opioidintoxication and estimated glomerular filtration rate (GFR) by the CKD-EPI-Formula. Indications for opioid prescriptions were either categorised as 'neoplastic disease', 'musculoskeletal' (which comprised degenerative, traumatic and autoimmune diseases of the locomotor system) or 'other'. The outcomes 'constipation', 'vertigo', 'delirium', 'pain', 'opioid intoxication' and 'presentation due to opioid therapy' were flagged if stated as such in the discharge report. Data on the duration of opioid therapy and the actual usage of on-demand prescriptions were not consistently available and thus were not analysed.

Chart reviews and data extraction were performed by the same three persons (BW, PB, SR), who are all trained medical professionals. The criteria for abstraction were predefined and explained in detail to the researchers. All cases that could not be classified clearly with the initial criteria were marked as 'unclear' and reviewed by the same person (BW). Apart from that, no monitoring of the chart abstraction was performed. We did not assess interobserver reliability. Data were stored in a central database in an anonymised fashion.

\section{Statistical methods}

Out of 1923 dosages of opioids, 94 (4,9\%) were missing and imputed from the median doses of the respective opioid. In 6737 patients (25.7\%), a GFR >90 was imputed from a normally distributed value between 91 and 130 .

After completion of data collection, data were cleaned and outliers ( $>95 \%$ CI) were reconfirmed or corrected. Data were exported to a statistical software package (SPSS for Windows, V.23) for analysis. Continuous data are presented as the median and interquartile ranges. The distribution of continuous variables was assessed using normal plots, and logarithm transformation was performed when appropriate. Categorical data are presented as absolute counts and per cent. Between-group comparisons of continuous variables were performed using one-way ANOVA and the Bonferroni test for post hoc comparisons. Categorical variables were compared using the $\chi^{2}$ test or Fisher exact test. Logistic regression was used to explore the association of opioid intake with death, length of stay, 72-hour reconsultation in the ED and 30-day rehospitalisation. Binary logistic regression was used to identify risk factors for mortality, 72 hours reconsultation rate to the $\mathrm{ED}, 30$-day rehospitalisation rate and overall length of stay. Based on biological plausibility and 


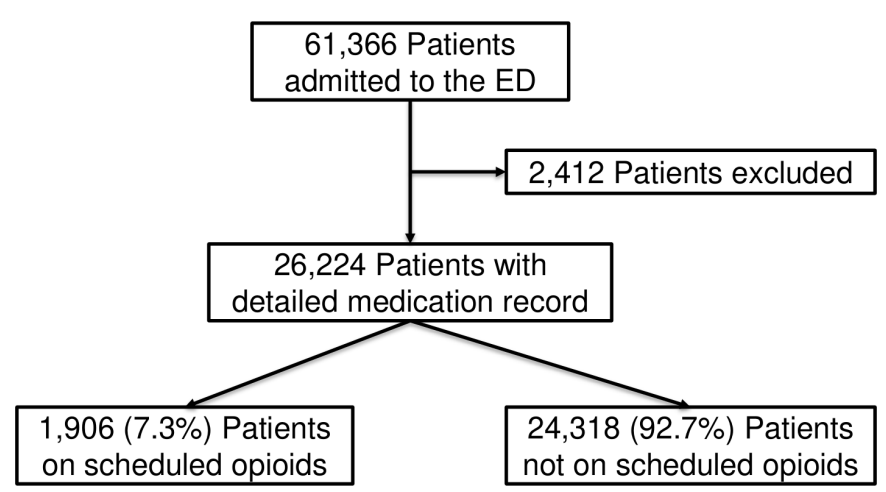

Figure 1 Flow diagram of patient selection and group allocation. Data abstraction was performed on all 26224 patients with detailed medication records; 2412 patients were excluded due to being younger than 18 years of age; no patient had a documented withdrawal of consent. ED, emergency department.

to adjust for confounders, multivariable logistic regression analysis was used by entering the three predefined covariates age, sex and GFR into the model. A two-sided $p$ value $<0.05$ was considered statistically significant.

\section{Patient and public involvement}

There was no patient or public involvement in the design or planning of the present study.

\section{RESULTS}

During the study period, 61366 ED consultations from a total of 19039 patients were recorded; $76.8 \%$ of patients had $1,15.1 \%$ had $2,4.7 \%$ had $3 \%$ and $3.3 \%$ had $\geq 4$ consultations. Of these, 26224 consultations had details on the medication records and were thus included in the analysis, as shown in figure 1.

\section{Characteristics of study participants}

The median age of patients was 63 years (IQR 44-78 years), and $49.6 \%$ of patients were female individuals; $51.8 \%$ of patients needed hospitalisation. The 72 hours reconsultation rate to the $\mathrm{ED}(0.4 \%, 95 \%$ CI $0.29-0.43)$ and the 30-day rehospitalisation rate $(1.8 \%$, 95\% CI $1.66-$ 1.98) were generally low, and overall mortality was $1.9 \%$. The full baseline characteristics are shown in table 1.

\section{Types, dosage and indication of prescription opioids}

In this sample, 1906 patients $(7.3 \%)$ were taking scheduled opioids with a median daily morphine equivalent (MEQ) of $30 \mathrm{mg}$ (IQR 15-80.5 mg). The prevalence and median dosages of the individual opioids are shown in table 2. Non-opioid analgesics were used in only $50.1 \%$ of patients on chronic opioid analgesics.

Indications for opioid prescriptions were musculoskeletal in $1145(60.1 \%)$ patients, neoplastic disease in 374 $(19.6 \%)$ and other indications in 290 (15.2\%). In 340 cases $(17.8 \%)$, no indication for opioid intake could be identified by a detailed chart review.

\section{Complications related to opioid intake}

Falls, constipation and presence of delirium on admission to the ED were significantly more common in patients using prescription opioids. A comparison between patients taking scheduled opioids with patients not taking scheduled opioids regarding the associated complications is shown in table 1. One hundred fifty-four (8.2\%) ED visits from patients on scheduled opioids were considered to be related to opioid intake. Twenty-five patients taking opioid medication were admitted due to opioid intoxication $(1.3 \%, 95 \%$ CI $0.8-1.8)$; 3 of these patients had a cointoxication with alcohol, 9 with benzodiazepines and 1 with both alcohol and benzodiazepines.

Intake of scheduled opioids was found to be independently associated with the death of any cause (OR 2.76; 95\% CI 2.2-3.42), readmission to the ED within 72 hours (OR 2.69; 95\% CI 1.52-4.76) and rehospitalisation within 30 days (OR 3.57; 95\% CI 2.87-4.44), the detailed results of the logistic regression are shown in table 3 .

\section{Opioid prescription in patients with impaired renal function}

No difference in non-opioid analgesics use was observed when adjusted for the estimated glomerular filtration rate (eGFR). Although hydromorphone does not accumulate in patients with impaired renal function, it was sparsely used in our population. Hydromorphone was prescribed in only 18 patients, and no patient had an eGFR below $30 \mathrm{~mL} / \mathrm{min}$. In contrast, 97 patients on chronic opioids other than hydromorphone had an eGFR between 15 and $29 \mathrm{~mL} / \mathrm{min}(8.1 \%)$, and 24 patients had an eGFR below $15 \mathrm{~mL} / \mathrm{min}(2.0 \%)$. Of the 25 patients presenting with opioid intoxication, 2 had an eGFR between 15 and $29 \mathrm{~mL} / \mathrm{min}$ and 2 had an eGFR below $15 \mathrm{~mL} / \mathrm{min}$.

\section{DISCUSSION}

In the present study, we found a prevalence of $7.3 \%$ for prescription opioid use in patients presenting to the ED. The musculoskeletal disease was the main indication for opioid use, outnumbering neoplastic disease three times. The use of prescription opioids was independently associated with 72-hour ED reconsultation, 30-day rehospitalisation and in-hospital mortality. Only one in two patients using opioid medication also used non-opioid baseline analgesics. This study was conducted in a large population of ED patients from a wide spectrum of socioeconomic backgrounds since Swiss mandatory health insurance requests beneficiaries seek treatment in their province of residence and our hospital is the only regional provider. This gives a potential bias to our data, as more expensive private insurance lifts that limitation. Additionally, this is one of the first studies conducted in continental Europe.

The finding of this study that patients using prescription opioids are older with a female predominance is similar to previous findings. ${ }^{13}$ Oxycodone and fentanyl were the most commonly prescribed opioids. Interestingly, only approximately half of patients taking prescription opioids in our collective also used other analgesics, as recommended by 
Table 1 Baseline characteristics

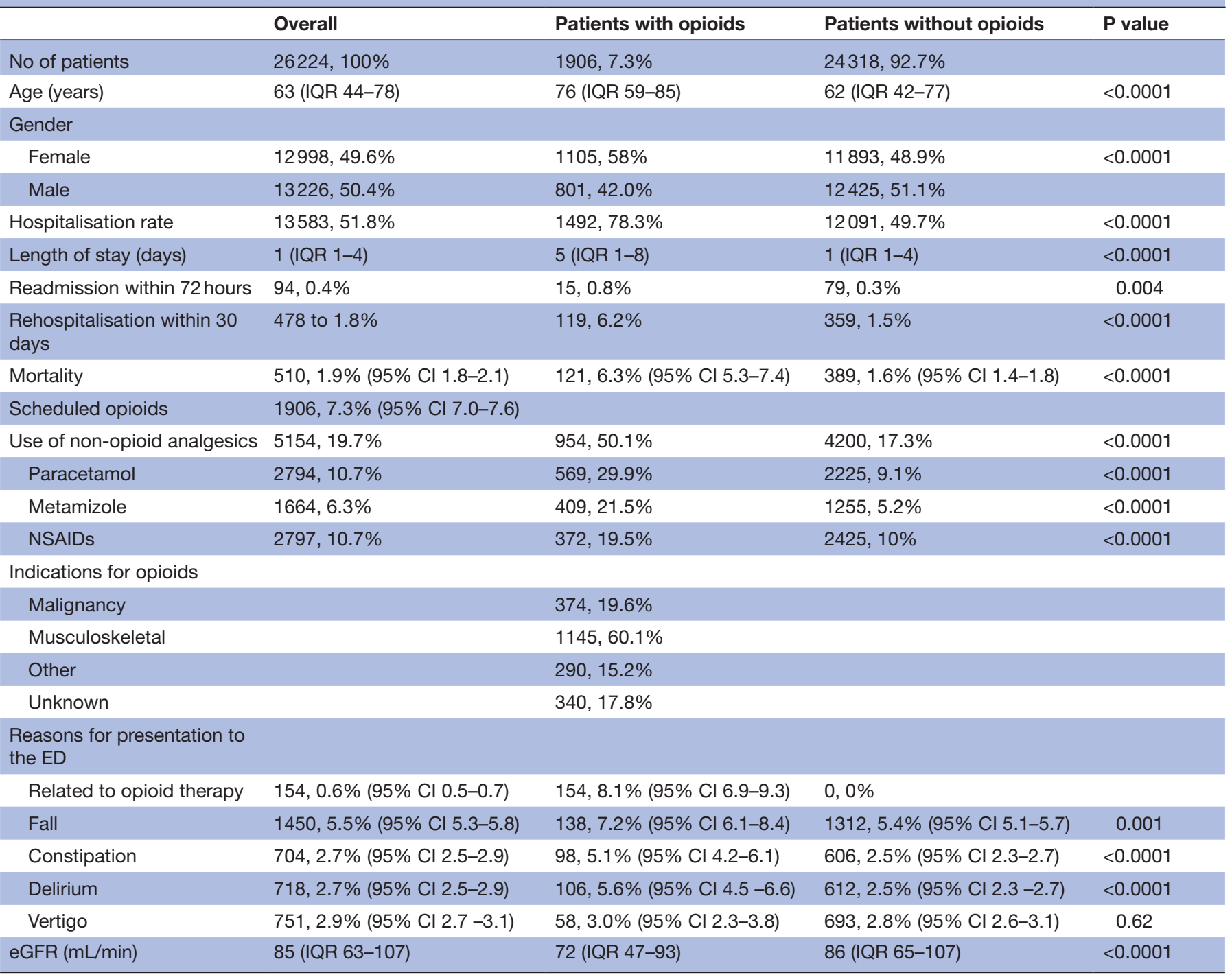

ED, emergency department; eGFR, estimated glomerular filtration rate (CKD-EPI formula); NSAIDs, non-steroidal anti-inflammatory drugs.

the WHO analgesic ladder scheme. This, in addition to the finding that musculoskeletal pain is the primary indication for opioid prescription raises the question of whether opioid prescription practices are too permissive.

Although the present findings show that adverse events due to prescription opioids, especially intoxications, are not highly prevalent in our population, we showed that ED consultations due to complaints such as constipation, falls or delirium were significantly more common in patients on prescription opioids. These findings also support data from Daoust et al, where any side effects were reported in $79 \%$ and constipation in $38 \%$ of patients taking opioids in a prospective evaluation of opioid side effects. ${ }^{15}$ Moreover, in the present study, more 72-hour ED reconsultations, a higher need for hospitalisation as well as 30-day rehospitalisation were found in patients taking opioids on a regular basis. These data are supported by previous investigations where $53 \%$ of the ED visits for opioid overdose resulted in hospitalisation and $10 \%$ led to a near-fatal event. ${ }^{16}$ This poses a significant burden for EDs, hospitals and insurers.

Compared with the USA, little data on the prevalence, indications and potential complications of prescription opioids in European ED patients exist. To the best of our knowledge, this is the first study providing data on this issue from a central European collective of patients. As stated above, the rate of opioid misuse and opioid-related mortality are considerably less in Europe than in the USA. Additionally, more opioid-dependent patients are enrolled in treatment programmes in Europe. ${ }^{9}$ Our study reproduces results from the USA insofar as oxycodone and fentanyl are the most frequently used preparations ${ }^{7}$ and musculoskeletal pain is the primary indication for opioid prescription. ${ }^{17}$ In view of the above, the prescription patterns in our Swiss collective are similar to those reported in the USA. Previous studies have shown an increased rate of opioid-related complications exceeding a MEQ of $50 \mathrm{mg} / \mathrm{d}^{1819}$ and increased mortality for doses 
Table 2 Prevalence and dosages of opioids

\begin{tabular}{lcc}
\hline & Patients, $\mathbf{n}(\%)$ & $\begin{array}{l}\text { Dose (mg), median } \\
\text { (IQR) }\end{array}$ \\
\hline Morphine equivalent & $1906(100)$ & $30(15-80.5)$ \\
Morphine & $169(8.9)$ & $40(20-160)$ \\
\hline Hydromorphone & $18(0.9)$ & $12(8-16)$ \\
\hline Transdermal fentanyl & $401(21.0)$ & $0.6(0.6-1.8)$ \\
\hline Sublingual buprenorphine & $19(1.0)$ & $6(2-16)$ \\
\hline Transdermal & $18(0.9)$ & $0.84(0.84-1.68)$ \\
buprenorphine & & \\
\hline Tramadol & $316(16.6)$ & $100(75-150)$ \\
\hline Hydrocodeine & $10(0.5)$ & $16.5(10-30)$ \\
Codeine & $130(6.8)$ & $60(30-90)$ \\
\hline Levomethadone & $3(0.2)$ & $10(10-10)$ \\
\hline Methadone & $118(6.2)$ & $80(35-200)$ \\
\hline Oxycodone & $92(4.8)$ & $20(15-30)$ \\
\hline Oxycodone/naloxone & $667(35.0)$ & $20(10-40)$ \\
\hline Tapentadol & $102(5.4)$ & $150(100-200)$ \\
\hline Tilidine & $1(0.1)$ & $150(150-150)$ \\
\hline Pethidine & $3(0.2)$ & $50(50-400)$ \\
\hline
\end{tabular}

Doses are given for the respective opioid. For oxycodone/naloxone, only the oxycodone dose was used. The conversion factors for the morphine equivalent calculation are as follows: hydromorphone, 4.5; transdermal fentanyl, 2.4; sublingual buprenorphine, 0.1; transdermal buprenorphine, 2.3; tramadol, 0.13; hydrocodeine, 0.13; codeine, 0.13 ; levomethadone, 16 ; methadone, 8 ; oxycodone, 1.5 ; oxycodone naloxone, 1.5 ; tepentadole, 0.3 , tilidine, 0.2 ; pethidine, $0.4 .^{25}$

larger than $200 \mathrm{mg} / \mathrm{d} .{ }^{20}$ The reported median MEQ in the USA varies from $6.0^{19}$ to $53.6 \mathrm{mg} / \mathrm{d}^{21}$ In context, our study population had a median MEQ of $30 \mathrm{mg} / \mathrm{d}$, with the highest dosages for methadone. Thus, the dosages of opioids in the European and the US population seem comparable. Therefore, we assume that the current opioid crisis in the USA is not dose-related but due to the factors proposed by Fisher et al, including questionable promotion campaigns of the pharmaceutical industry, increased patient demand for 'effective treatment' and permissive prescription practices. ${ }^{22}$ In Switzerland, on the other hand, prescription opioids are restricted substances, and prescription as well as distribution are strictly regulated and controlled by the government. Furthermore, it is illegal to promote restricted substances to the general public.

The present study has several limitations: first, data on medication were extracted from electronic patient charts available in only $42 \%$ of all cases, and therefore, there is a possibility of selection bias. However, our electronic records do not differentiate between missing data and simply not-scheduled medication, which is expected to be the case in a significant part of a population with a median age of 63 years. Second, patients taking nonprescription opioids or opioids on an as-needed basis could not be considered in the analysis as quantification of the actual daily dose was not possible. Missing data on non-opioid analgesics purchased over the counter and not reported by the patient remain unknown. In Switzerland, common analgesics such as paracetamol and ibuprofen are available over the counter but only in a very limited quantity. Furthermore, the purchase is reimbursed by the insurance if prescribed by a physician, and we captured over the counter medication in our records as those are medically relevant. Third, under-reporting of adverse events of opioid therapy due to treatment by the primary care physician or another institution should be considered. Fourth, even though a large group of ED patients was investigated, our data stem from a single hospital and may not be generalisable to other settings in Switzerland or other European countries. Fifth, there is the possibility of residual confounding in retrospective studies. Sixth, no pilot testing of the data abstraction instrument was performed, abstractors were not blinded to the study hypothesis and there was no testing for interrater reliability. Seventh, it has to be noted that outcomes concerning the need for hospitalisation, 72-hour ED reconsultation, 30-day rehospitalisation and mortality are associations, and causality cannot be proven. Of course, opioid analgesics are often needed to treat pain and dyspnoea in patients with an underlying malignancy, who may have higher rates of adverse outcomes. However, it must be noted that in our study, only approximately $20 \%$ of patients using opioids had an underlying malignancy. Nevertheless, it cannot be excluded that adverse outcomes of opioid users can causally be attributed to

Table 3 Multivariate regression analysis of the impact of age, sex, intake of scheduled opioids and eGFR on mortality, readmission within 72 hours, rehospitalisation within 30 days and length of stay

\section{OR (95\% Cl; p)}

\begin{tabular}{llllll}
\hline & Mortality & Readmission within 72hours & Rehospitalisation within $\mathbf{3 0 ~ d ~}$ & $\begin{array}{l}\text { Length of stay } \\
(\mathbf{l o g a r i t h m i s e d}), \mathbf{p} \text { value }\end{array}$ \\
\hline Age & $1.047(1.036-1.059 ;<0.001)$ & $0.989(9.73-1.005 ; 0.17)$ & $1.002(0.994-1.009 ; 0.664)$ & $<0.001$ \\
Sex & $1.651(1.292-2.110 ;<0.001)$ & $0.76(0.454-1.272 ; 0.296)$ & $1.109(0.884-1.390 ; 0.371)$ & 0.496 \\
Opioid intake & $2.916(2.193-3.876 ;<0.001)$ & $2.543(1.224-5.283 ; 0.012)$ & $3.630(2.771-4.755 ;<0.001)$ & $<0.001$ \\
eGFR & $0.980(0.975-0.986 ;<0.001)$ & $1.002(0.990-1.014 ; 0.725)$ & $0.986(0.981-0.991 ;<0.001)$ & $<0.001$ \\
\hline
\end{tabular}

Mortality depicts in-hospital mortality only. GFR was chosen as a surrogate marker for comorbidity as we did not systematically abstract comorbidities.

eGFR, estimated glomerular filtration rate. 
their underlying disease, which might be the reason for opioid prescriptions. Lastly, kidney injury is not only expected to occur in advanced diabetes mellitus and arterial hypertension but also in heart failure ${ }^{23}$ and nonalcoholic fatty liver disease,${ }^{24}$ many severe chronic conditions do not impair kidney function. This is a limitation of our multivariate model where we used eGFR as the only marker for comorbidity.

In conclusion, the present study showed that prescription opioid use is common and the prescription patterns are similar to those reported in the USA. However, as many as one in two patients did not have baseline non-opioid analgesia as recommended by the WHO ladder scheme. Opioid-related symptoms such as incoordination leading to falls, constipation and delirium were significantly more common in opioid users. Moreover, prescription opioid users were prone to need hospitalisation, reconsulted the ED within 72 hours and needed rehospitalisation within 30 days.

Acknowledgements This manuscript was edited for proper English language, grammar, punctuation, spelling, and overall style by American Journal Experts.

Contributors BW and GL had the idea for the study and prepared the study protocol. BW, PB and SR performed data mining and created the research database. G-CF supervised the data quality and performed statistical analysis. BW and GL wrote the manuscript draft. BW, GL, PB, SR, G-CF and AKE critically reviewed and revised the manuscript.

Funding The authors have not declared a specific grant for this research from any funding agency in the public, commercial or not-for-profit sectors.

Competing interests None declared.

Patient and public involvement Patients and/or the public were not involved in the design, or conduct, or reporting, or dissemination plans of this research.

Patient consent for publication Not required.

Ethics approval This study was approved, and the need to acquire informed consent from individual patients waived by the Ethics Committee Nordwest und Zentralschweiz (www.eknz.ch, Project ID 2019-01654).

Provenance and peer review Not commissioned; externally peer reviewed.

Data availability statement № data are available. No additional data available.

Open access This is an open access article distributed in accordance with the Creative Commons Attribution Non Commercial (CC BY-NC 4.0) license, which permits others to distribute, remix, adapt, build upon this work non-commercially, and license their derivative works on different terms, provided the original work is properly cited, appropriate credit is given, any changes made indicated, and the use is non-commercial. See: http://creativecommons.org/licenses/by-nc/4.0/.

ORCID iD

Bertram K Woitok http://orcid.org/0000-0001-7328-5017

\section{REFERENCES}

1 Todd $\mathrm{KH}$. A review of current and emerging approaches to pain management in the emergency department. Pain Ther 2017;6:193-202.
2 Butler MM, Ancona RM, Beauchamp GA, et al. Emergency department prescription opioids as an initial exposure preceding addiction. Ann Emerg Med 2016;68:202-8.

3 Upadhye S. Creating opioid dependence in the emergency department. CJEM 2018;20:100-3.

4 Hoppe JA, Kim H, Heard K. Association of emergency department opioid initiation with recurrent opioid use. Ann Emerg Med 2015;65:493-9.

5 Weiner SG, Horton LC, Green TC, et al. A comparison of an opioid abuse screening tool and prescription drug monitoring data in the emergency department. Drug Alcohol Depend 2016;159:152-7.

6 Pedigo JR, Seifert CF. Rate of patients at elevated risk of opioid overdose visiting the emergency department. Am J Emerg Med 2018;36:2161-5.

7 Bosetti C, Santucci C, Radrezza S, et al. Trends in the consumption of opioids for the treatment of severe pain in Europe, 1990-2016. Eur $J$ Pain 2019;23:697-707.

8 Kalkman GA, Kramers C, van Dongen RT, et al. Trends in use and misuse of opioids in the Netherlands: a retrospective, multi-source database study. Lancet Public Health 2019;4:e498-505.

9 van Amsterdam J, van den Brink W. The misuse of prescription opioids: a threat for Europe? Curr Drug Abuse Rev 2015;8:3-14.

10 O'Connor S, Grywacheski V, Louie K. At-a-glance - Hospitalizations and emergency department visits due to opioid poisoning in Canada. Health Promot Chronic Dis Prev Can 2018;38:244-7.

11 Marco CA, Mann D, Rasp J, et al. Effects of opioid medications on cognitive skills among emergency department patients. Am J Emerg Med 2018;36:1009-13.

12 Grewal K, Austin PC, Kapral MK, et al. The impact of opioid medications on subsequent fractures in discharged emergency department patients with peripheral vertigo. CJEM 2018;20:28-35

13 Daoust R, Paquet J, Lavigne G, et al. Impact of age, sex and route of administration on adverse events after opioid treatment in the emergency department: a retrospective study. Pain Res Manag 2015;20:23-8.

14 Owsiany MT, Hawley CE, Triantafylidis LK, et al. Opioid management in older adults with chronic kidney disease: a review. Am J Med 2019;132:1386-93.

15 Daoust R, Paquet J, Cournoyer A, et al. Side effects from opioids used for acute pain after emergency department discharge. Am J Emerg Med 2020;38:695-701.

16 Hasegawa K, Brown DFM, Tsugawa Y, et al. Epidemiology of emergency department visits for opioid overdose: a populationbased study. Mayo Clin Proc 2014;89:462-71.

17 Bohnert ASB, Valenstein M, Bair MJ, et al. Association between opioid prescribing patterns and opioid overdose-related deaths. JAMA 2011;305:1315-21.

18 Saunders KW, Dunn KM, Merrill JO, et al. Relationship of opioid use and dosage levels to fractures in older chronic pain patients. $J$ Gen Intern Med 2010;25:310-5.

19 Dunn KM, Saunders KW, Rutter CM, et al. Opioid prescriptions for chronic pain and overdose: a cohort study. Ann Intern Med 2010;152:85-92.

20 Gomes T, Mamdani MM, Dhalla IA, et al. Opioid dose and drugrelated mortality in patients with nonmalignant pain. Arch Intern Med 2011;171:686-91.

21 Braden JB, Russo J, Fan M-Y, et al. Emergency department visits among recipients of chronic opioid therapy. Arch Intern Med 2010;170:1425-32.

22 Fischer B, Keates A, Bühringer G, et al. Non-medical use of prescription opioids and prescription opioid-related harms: why so markedly higher in North America compared to the rest of the world? Addiction 2014;109:177-81.

23 Grande D, Gioia MI, Terlizzese P, et al. Heart failure and kidney disease. Adv Exp Med Biol 2018;1067:219-38.

24 Marcuccilli M, Chonchol M. Nafld and chronic kidney disease. Int J Mol Sci 2016;17:562.

25 Preston B, Imfeld P. Umrechnungsfaktoren zur Opioidrotation, 2019. Available: https://www.unispital-basel.ch/fileadmin/unispitalbaselch/ Bereiche/Querschnittsfunktionen/Spital-Pharmazie/Aequivalenz Opioide.pdf [Accessed 11 Aug 2016]. 